\title{
Does renewable energy consumption contribute to the development of low-carbon economy? Evidence from China
}

\section{Tuochen Li}

Harbin Engineering University

Ziyi Shi ( $\sim$ szy@hrbeu.edu.cn)

Harbin Engineering University

Dongri Han

Harbin Engineering University

\section{Research Article}

Keywords: Renewable energy consumption, Low-carbon economy development, Threshold effect, Regional heterogeneity, Ecological footprint

Posted Date: February 24th, 2021

DOl: https://doi.org/10.21203/rs.3.rs-227389/v1

License: (c) (i) This work is licensed under a Creative Commons Attribution 4.0 International License. Read Full License 


\title{
Does renewable energy consumption contribute to the development of
}

\section{low-carbon economy? Evidence from China}

\author{
Tuochen Li, Ziyi Shi ${ }^{* 1}$, Dongri Han
}

Institution: School of Economics and Management, Harbin Engineering University, Heilongjiang, 150001, China

Abstract: Stimulating renewable energy consumption has become a major strategic choice for China to both fulfill the international commitment to reduce carbon emissions and realize the high-quality growth of the domestic economy. On account of the provincial data during the period of 2000 to 2017, we creatively incorporate the ecological footprint into the measurement of low-carbon economy development level through super-efficient SBM model, so as to infer the coordinated development level of 3E system more precisely. Based on factor substitution effect, energy path dependence effect and scale effect, the complex nonlinear relationship between the two core research objects is further probed by constructing the threshold regressive model. On the foundation of heoretical research, the consumption of renewable energy, the intensity of energy use and the level of regional economic development are respectively selected as the moderating variables of the model. Further, we divide different intervals of threshold values to distinguish the differences in the effects caused by regional heterogeneity. The following conclusions are drawed ultimately: There is an apparent threshold effect between the renewables consumption and the advancement of low-carbon economy. Only when the renewable itself reaches a higher level of consumption, can it show a significant advantage in green economic development. In addition, to make full use of the renewable resources to boost low-carbon and green economy, it is necessary to reduce the economy's dependence on energy, that is, to decrease the intensity of energy use, while maintaining the process of improving coordination of regional economy.

Key words: Renewable energy consumption; Low-carbon economy development; Threshold effect; Regional heterogeneity; Ecological footprint

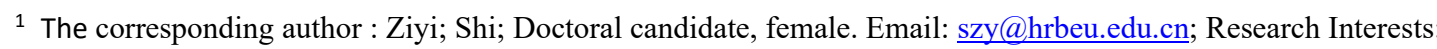
energy economy, environmental economy and technical innovation
} 


\section{Introduction}

With the intensified contradiction between economic growth and ecological preservation, the green economy has attracted more and more attention from various countries (regions). The idea of "low carbon economy" (LC economy), which is closely linked with technological innovation and energy transition, was first introduced in the "Energy White Paper" promulgated by the United Kingdom in 2003. Guided by the practice of sustainable development, it contains an economic development model that aims to achieve mutual benefit and win-win outcome on the both side of economy and ecology with minimum consumption of dirty energy (coal, oil, etc.) and greenhouse gases. Featured with low energy u and less pollution, the development pattern of LC economy is not merely a major innovation for social progress, but also a critical social reform to carry forward a series of technologies in energy-saving and pollution control.

Currently, the global energy consumption, which is typified by fossil fuels, has caused a whole set of energy issues and environment problems, including ozone layer destruction, greenhouse gas emissions, etc. (Zhu et al. 2020). To varying degrees, countries in the world are faced with a common practical problem -- ecological deterioration and serious environmental pollution, among which China's predicament is more prominent. In the context of the accelerated pace of worldwide industrialization and urbanization, the global energy consumption, especially the expense of traditional fossil energy, is expanding year by year, which further leads to the continuous rise of total carbon dioxide emissions (Yang et al. 2021). According to the IEA (International Energy Agency), the emissions of green gases related to energy use have reached unprecedented levels. Fatally, the utilization of energy resources and 
the emissions of carbon dioxide have risen by a third in 2020 and are set to double by 2050 . The large amount of high energy consumption dominated by fossil fuels and the sharp increase of carbon dioxide emissions have brought severe challenges to sustainable economic growth, resulting in the energy structure adjustment being a vital issue of concern to all countries (Wang et al. 2020). The European Parliament has set the target of raising the share of clean power in the total energy use of the EU to $35 \%$ by 2030 . And as the largest developing country, China also demands to enlarge the percentage of non-fossil fuels to twenty persents by the year of 2030. At present, realizing the transformation of energy consumption structure has become one of the momentous development strategies of all countries, during when the topic of global clean energy governance has also been regarded as a pivotal academic research since the 21 st century (Zhu 2020; Xu 2020). At the 75th session of the United Nations General Assembly in September 2020, Chinese President Xi stressed increasing China's outstanding contribution in adopting more forceful policy measures to peak the $\mathrm{CO}_{2}$ discharge by 2030 and determined to surpass es carbon neutrality until 2060. Notably, the speech has been one of the most considerable climate commitments yet made by the world.

However, on account of the significant diversities in the industrial structure, resource endowment and technological level among different regions in China, there remains striking discrepancies in energy consumption structure and economic development among various regions (Xiao 2019). Whether it is scientific and appropriate to blindly set uniform standards for clean fuels or renewable energy still remains discussing. On this basis, this research argues that when discussing the impact of the renewables utilization on the LC economy, instead of simply studying a linear impact between the two, it is of vital significance to comprehensively 
consider the regional heterogeneity factors to explore whether the consumption of the renewable sources can contribute to the green development. Furthermore, does the magnitude or the effect of the influence differ from region to region? If so, what is the determining factors behind it? The specific detection of these doubts may well contain the practical implication of reshaping the industrial structure and adjusting the proportion of energy for China's future, thus realizing the high-quality economy advance with minimal environmental loss.

\section{Literature review}

Energy, as an important production factor, is included in the production function model along with capital, labor and other factors (Ma et al. 2018). It is imperative to boost the green transition of the whole social and economic production in that both the finiteness and hazards of fossil energy are becoming an increasingly serious problem worldwide, and energy security issues such as the bottleneck of crude oil supply have become prominent(Qi and Li 2018).

Scholars have started studying the correlation between the energy structure and economy development, attaching increasing importance to the positive externality of adjusting energy consumption structure. Nevertheless, due to the diversity in sample selection, empirical methods and research objects, there are striking differences in the research findings. On the one side, some scholars apply renewable energy to the production function and regard it as a production factor, discovering that traditional highly polluting energy can be replaced by clean energy to some extent, which is conducive to energy diversification and energy diversification and climate mitigation, thus promoting economic growth together with other production factors.

Taking OECD countries as research samples, Inglesi-Lotz (2015) proposed that the utilization of the renewables can significantly advance sustainable economy, which was also verified by 
Armeanu et al. (2017) through empirical models of 28 countries in Europe. Similarly, by means of ARDL method and the sample of G-7 countries, Cai et al. (2018) proved the favorable influence of energy consumption transition on economy increase as well.

On the other hand, some scholars hold the point that in comparison with polluting energy sources, the present evolution of the renewable sources produce neither the technological superiority nor cost advantages. At this stage, the progress of the renewables is primarily actuated by government policies, which hides a certain opportunity cost, causes quite a few economic losses and goes against the productivity improvement (Qi 2018). Based on the empirical test of ADLM, Ocal and Aslan (2013) explored the causality between the renewables use and economic increase in Turkey, and the findings showed that renewable energy consumption in not beneficial to the economy. Moreover, other scholars have suggested that renewable energy consumption may not have evident impact on productivity as expected. Applying panel data in Brazil and Malaysia during the period from 1971 to 2011, Destek (2016) found that there is no obvious linkage between renewable energy utilization and economy advance; Combined with the data of the United States from 1949 to 2006, Bowden and Payne(2010) found that it appears no necessary correlation in the spending of clean energy in business and industry either, after conducting empirical tests on the sub-industrial sectors.

Furthermore, for the past few years, some researchers have discovered the regional variation in the effect of the renewables utilization on economy development. By carrying out the data analysis concerning economic gain and energy consumption structure of G20 countries, Sikder et al. (2019) pointed out that the renewables do not have the same impact on economic output in various countries. For example, in countries such as the United States, Italy and 
115 Argentina, the consumption of renewable energy can powerfully impel economy growth; And 116 similarly, by comparing the linkage between the renewables and productivity in both developed 117 and developing countries, Omri et al. (2015) put forward that in advance countries such as 118 Netherlands and Japan, there is a one-way causal correlation between renewable sources 119 utilization and economy gain.

120 Current studies related to the renewable use and economic development authentically 121 provide the theoretical basis for this paper. However, there remains some room for 122 improvement in the previous literature. For one thing, the above literatures mainly studied the 123 influence of the renewables on economic development and regional differences by means of 124 linear methods and grouping methods. But in fact, since the application of the non-fossil fuels 125 affects economy advance through a variety of mechanisms, there is probably a nonlinear panel threshold test method is exploratively introduced into the analysis of the non-linear 
existence of non-linear impact are accurately identified; Secondly, the mechanism of each threshold variable is deeply analyzed, and effects such as the factor substitution effect of the renewables, the path dependence effect of energy use and the technological base effect of economy on the increase of the clean energy consumption are further proposed; Thirdly, in terms of economic significance and classical literature, the measurement index of each factor of production in the production function has been comprehensively improved. Among them, the contribution of ecological footprint to economic growth has been creatively valued, and thus the level of regional low-carbon economic development can be accurately estimated.

\section{Theoretical analysis}

As the major features of the transition of economy mode, the allocation structure adjustment of the three basic elements of capital, labor and energy plays a fundamental role on economy advance (Liu et al. 2018). In the context of "restructuring for transformation", it is increasingly urgent to adjust the configuration structure of energy elements and promote the clean transformation of the energy system dominated by fossil energy for low-carbon development. Yet, we have to realize that as non-fossil energy has developed rapidly, the adjustment of energy structure, which is characterized by the renewable energy consumption, is definitely possible to have more than a purely stimulative impact on economy (Lin 2017). In other words, under the action of some regulatory mechanisms, the relationship between the two may present a structural evolution. What is noteworthy is that the panel threshold regression model is a nonlinear econometric model, whose connotation is to incorporate the regulated index as an unknown factor into the model equation, establish the piecewise regression function based on the core independent variable, thereby estimating both the inflection point value of 
threshold mechanism and its related parameters. Therefore, we apply the conventional nonlinear model, namely the threshold regression model, to the study of the impact relationship between the renewables consumption and green development. Furthermore, based on the following theoretical analysis and mechanism research, this paper attempts to raise three hypotheses.

(1) The consumption of renewable energy. In the process of increasing the utilization of renewable energy, the overall energy structure is also facing slow evolution, which is embodied in the transformation of the energy system from fossil fuels to clean energy (Koak 2017). However, the impact of the two energy systems on the economic and social system is bound to be different, especially on the economic growth. More precisely, when fossil energy is dominant in the energy system, the economic cost of energy use is small, but its negative externality to the ecological environment is more obvious, which is reflected in the enhancement of greenhouse effect, thus leading to the global warming (OMRI 2021; Naqvi et al. 2020). At the same time, because of the un-producible essence of fossil energy and the overexploitation of fossil fuels by human beings, the traditional energy sources are running out, which also makes economies that have long relied on fossil energy consumption face uncertainty in energy security ( $\mathrm{Li}$ and Cheng 2020). On the contrary, when the energy system is dominated by non-fossil energy, the economic cost of energy use will be large, and the negative externalities brought by energy use will be greatly weakened, which will impose a correspondingly large influence on the economic systems, significantly strengthening the social sustainable development ability (Xie et al. 2018). However, boosting non-fossil energy consumption does not happen overnight at all. In the preliminary stage of the increase of 
181

182

non-fossil energy consumption, the production process and equipment need to be updated in time, the clean production capacity of enterprises needs to be improved, and the relevant market of products also needs to be redefined. Consequently, renewable energy consumption may impose huge economic cost on the economic growth of enterprises, thereby inhibiting the advancement of the green economy (Teng and Rong 2020; Li and Yi 2020). When the cleanliness of the energy system is continuously improved, the driving effect of non-fossil energy consumption on ecological environmental protection and economic development is gradually highlighted, and thus it will exert a favorable influence the green economic development. Therefore, this study considers that in the process of renewable energy consumption, there must be a special point through which the renewable energy consumption breaks, its impact on the evaluation of LC economy will change from negative to positive, displaying an obvious "J" curve effect.

On such a basis, this article comes to formulate Hypothesis 1: Renewable energy consumption does not linearly affect the green economy. Accompanied by the continuous advancement of the renewables consumption, its influence on the development of low-carbon economy may well undergo a structural mutation, with the effect direction changing from suppressive to stimulative.

(2) The intensity of energy consumption. The energy intensity refers to the energy use per unit of real GDP, reflecting the degree of energy dependence of an economy (Luan et al. 2021). As the energy consumption intensity reaches a certain level, the economic development becomes highly dependent on energy consumption, with more apparent path dependence effect and lock-in effect of energy use (Qi and Li 2017). Combining the idea of path dependence with 
203

204

205

the energy economy, this paper aims to discuss the high dependence and internal inertia of the system on the production, technology and industrial structure of fossil energy driven by the economic development due to the scale effect, adaptive expectation, cooperative effect and other factors (David 1988; Arthur 1994). Unruh (2000) pointed out that due to the increasing economies of scale in energy path dependence, the industrial economy would be locked into the energy system based on fossil fuels for a long time, which would hinder the policy and market forces of the renewables. And for a very long time, under the extensive economic development mode of high input and low output, China has also generated serious energy dependence and lock-in effect on fossil energy. Especially in the middle parts and the western areas, it is hard to change the facilities construction and corresponding policies and systems that have been formed for fossil energy consumption.

In consideration of the above analysis, this study puts forward Hypothesis 2: Under the adjustment of the energy intensity, the renewables' influence on low-carbon economy appears as a nonlinear shock. Specially, when energy intensity exceeds the threshold value, it limits the beneficial effect of the renewables consumption on the green economy to some extent.

(3) The level of economic development. The relationship between economic advance and energy consumption usually follows the rules described by the environmental Kuznets curve. In regions with better development of economy, the energy resources and economic system are dramatically decoupled with smaller economic cost of energy substitution, and the diversified energy structure formed by factor substitution may contribute to the economic growth (He and Lin 2019; Presley et al. 2020). Generally speaking, areas with higher levels of economic development tend to possess the hardware foundation (such as investment in scientific research, 
infrastructure, etc.) and software foundation (such as consciousness of green development and ecology protection, reservation of professional knowledge, etc.) required by non-fossil energy consumption. Under such conditions, no matter at the policy level or the market level, there are few obstacles to the consumption of non-fossil energy. Additionally, a higher level of economic development often leads to the continuous enrichment of enterprises' investment in education funds and scientific research and innovation, thus attracting more social capital, cutting-edge technology and high-tech talents, which are conducive to the formation of aggregation effect (Zhao and Lin 2019). After dividing 108 countries into four groups: high income, low income and two types of middle incomes between the two, Al-Mulali et al. (2013) concluded that the higher the income level, the greater the sustainable and significant positive impact of the renewables utilization on economy advance; Based on the panel data of $28 \mathrm{EU}$ member states, Qi and Li (2017) indicated that activities related to renewable energy have significant economic costs and are detrimental to economic growth. Besides, the inhibition effect of the renewables on economy progress is visibly disparate in countries with various economic development levels; Huang et al. (2008) grouped 82 countries by the income level, finding that the energy consumption does not have the same effect on real GDP across groups, which was proved by Lee and Chang(2007) as well. It can be seen that once the economy climbs a certain height, the consumption of renewables will exert a completely opposite effect on green development.

On this basis, we further conceive the Hypothesis 3: The utilization of the renewables has a nonlinear impact on the progress of LC economy. Meantime, with a higher development level of economy, the driving effect of renewable energy consumption on the green economic advance is more evident. 


\section{Methodology and data}

249

\subsection{Econometric methodology}

\subsubsection{Setting of threshold model}

Borrowing from Hansen's (1999) findings, this study adopts a non-dynamic threshold model to examine the existence of threshold effect between the consumption of renewable energy sources and the green economy. As an econometric model of nonlinear relation test, this method can not merely precisely measure different values of the thresholds, but also statistically verify the significant level of endogenous "threshold characteristics". With renewable energy consumption $T E S_{i t}$, energy intensity Energy $y_{i t}$ and economic development level $G D P_{i t}$ as the moderating variables, the following single-threshold panel models are constructed.

$$
\begin{gathered}
L C E_{i t}=\theta+\beta_{1} G O V_{i t}+\beta_{2} I C T_{i t}+\beta_{3} U R B_{i t}+\beta_{4} P O P_{i t}+\beta_{5} R E G_{i t}+\beta_{6} O p e n_{i t}+\beta_{7} T E S_{i t} \times \\
I\left(T E S_{i t} \leq \gamma_{1}\right)+\beta_{8} T E S_{i t} \times I\left(T E S_{i t}>\gamma_{1}\right)+\varepsilon_{i t}
\end{gathered}
$$

$$
L C E_{i t}=\theta+\beta_{9} G O V_{i t}+\beta_{10} I C T_{i t}+\beta_{11} U R B_{i t}+\beta_{12} P O P_{i t}+\beta_{13} R E G_{i t}+\beta_{14} O p e n_{i t}+
$$

$$
\beta_{15} T E S_{i t} \times I\left(\text { Energy }_{i t} \leq \gamma_{2}\right)+\beta_{16} T E S_{i t} \times I\left(\text { Energy }_{i t}>\gamma_{2}\right)+\varepsilon_{i t}
$$

$$
L C E_{i t}=\theta+\beta_{17} G O V_{i t}+\beta_{18} I C T_{i t}+\beta_{19} U R B_{i t}+\beta_{20} P O P_{i t}+\beta_{21} R E G_{i t}+\beta_{22} O p e n_{i t}+
$$

$$
\beta_{23} T E S_{i t} \times I\left(G D P_{i t} \leq \gamma_{3}\right)+\beta_{24} T E S_{i t} \times I\left(G D P_{i t}>\gamma_{3}\right)+\varepsilon_{i t}
$$

In the above three formulas, LCE represents the degree of low-carbon economy. And three threshold variables in the corresponding models are respectively described by the consumption of the renewables $T E S_{i t}$, the intensity of energy use Energy ${ }_{i t}$ and the level of economic development $G D P_{i t}$. The formula also contains the same set of control variables, 
including government intervention $G_{0} v_{i t}$, informatization $I C T_{i t}$, urbanization $U R B_{i t}$, population density $P O P_{i t}$, environmental regulation $R E G_{i t}$ and the degree of openness Open $_{i t} . \beta$ expresses the vecor of coefficients, and $\gamma$ refers to the specfic value of the threshold. The formula also contains an index function $I(\bullet)$, whose value is 1 when the corresponding condition holds, otherwise is $0 . \varepsilon_{i t} \sim i d d\left(0, \delta^{2}\right)$ is the random interference.

\subsubsection{Examination methods of threshold effect} by deleting the average value within the group, and the single-threshold model is expressed in the form of matrix as follows:

$$
L C E_{i t}=x^{*}(\gamma) \beta+\varepsilon^{*}
$$

For a given value, the consistent estimator of the parameter $\beta$ can be gained through the common least square method, namely:

$$
\hat{\beta}(\gamma)=\left[\mathrm{X}^{*}(\gamma)^{\prime} \mathrm{X}^{*}(\gamma)\right]^{-1} \mathrm{X}^{*}(\gamma)^{\prime} \mathrm{Y}^{*}
$$
shown below respectively. obtained.

By minimizing $S_{1}(\gamma)$ corresponding to Equation 5, we can get the estimated value of $\gamma$, that is, $\hat{\gamma}=\arg \min _{\gamma} S_{1}(\gamma)$, from which the residual vector $\widehat{e^{*}}=\widehat{e^{*}}(\gamma)$ and the variance of the residual $\hat{\sigma}=\widehat{\sigma^{2}}(\hat{\gamma})=\frac{1}{n(T-1)} \widehat{e}^{\star} \widehat{e}^{*}=\frac{1}{n(T-1)} S_{1}(\hat{\sigma})$ can be further 
two aspects.

One is to examine whether there is a threshold effect, whose null hypothesis is $\mathrm{H}_{0}$ : $\beta_{1}=\beta_{2}$. Meantime, statistics are constructed for likelihood ratio test:

$$
F_{1}=\frac{S_{0}-S_{1}(\widehat{\gamma})}{S_{1}(\gamma) / n \widehat{(T-1)}}
$$

Among them, the specific value of the critical point cannot be identified on the basis of null assumption, which results in the non-standard distribution of traditional test statistics. Accordingly, Hansen(1999) proposed that by means of the self-sampling, the above deficiencies can be resolved effectively.

The other is to test whether the calculated threshold value is the same as the real value of the inflection point. Hansen(1999) proposed that the null hypothesis is still valid only by constructing a "non-rejection domain", that is, satisfying $L R_{1}\left(\gamma_{0}\right) \leq c(\alpha)$, where $c(\alpha)=$ $-2 \ln (1-\sqrt{1-\alpha})$. For the null hypothesis $\mathrm{H}_{0}: \beta_{1}=\beta_{2}$, the likelihood ratio statistic is:

$$
L R_{1}(\gamma)=\frac{S_{1}(\gamma)-S_{1}(\widehat{\gamma})}{\widehat{\sigma}^{2}}
$$

It is assumed that there is only one threshold in the above model, but once a double or multiple threshold value is tested in the model, it can be expanded on the basis of the above model. Due to space constraints, this article will not go into details.

\subsection{Variable description}

The explained variable: The level of low-carbon economy development $L C E$. As a sustainable development model with lower resource input and higher economic output, low-carbon economy mainly focuses on both input and output. In this paper, a super-efficiency DEA-SBM (a slacked-based DEA model) considering non-expected pollutions is adopted to estimate the level of low-carbon economic development which can 
313 effectively avoid the problem of efficiency overestimation and non-radial adjustment of input

314 and output efficiency. To be more precise, we assume that returns to scale are constant (Zhou

315 and $\mathrm{Hu} 2013)$. At the same time, this paper selects a output-oriented super-efficiency SBM

316 model and constructs an adjacent reference Malmquist index (Adjacent Malmquist). In the

317 choice of input and output indicators, referring to researchers such as Yan et al. (2020) and

318 Shen et al. (2020), the paper creatively adds the ecological footprint measured by the

319 improved emergence method (Yang and Zhu 2016; Tan and He 2016). Table 1 shows the

320 inputs of various biological accounts and energy accounts and the elements of input-output

321 listed in Table 2 are selected after careful consideration in the study.

Table 1 The index table of input and output

\begin{tabular}{cc}
\hline & Capital \\
Input & Labor \\
& Ecological footprint \\
\hline Output & Gross domestic product \\
& Carbon dioxide emissions \\
\hline
\end{tabular}

Table 2 Ecological footprint account

\begin{tabular}{cc}
\hline Land type & Species of biological resources \\
\hline Arable land & Cereals, beans, potatoes, cotton, oil plants \\
woodland & Wood, tea, fruit, apple, pear, grape \\
Grassland & Beef, pork, mutton, milk, poultry eggs \\
Fossil energy land & Crude oil, natural gas, kerosene, coke, diesel, gasoline, fuel oil, coal \\
Construction land & Electric power \\
Water area & Fish, shrimp, crabs and other aquatic products \\
\hline
\end{tabular}


327 framework of the Paris Agreement, the Chinese government has fully played its role as a

328 "responsible major country" and set targets for renewable energy consumption and carbon

329 reduction in China's development. At the policy level, the Chinese government has issued

330 three heavyweight documents: the 13th Five-Year Plan for Renewable Energy Development,

331 the 13th Five-Year Plan for Energy Development, and the Revolution Strategy for Energy

332 Production and Consumption 2016-2030. All of these documents set targets for renewable

333 energy consumption, basically stipulating the proportion of non-fossil energy in primary

334 energy consumption to $15 \%$ by $2020,20 \%$ by 2030 and $50 \%$ by 2050 . Increasing the

335 proportion of non-fossil energy consumption is undoubtedly the basic requirement for

336 promoting renewable energy consumption (Han et al. 2020). In this paper, the proportion of

337 non-fossil energy consumption in primary energy consumption is applied to characterize the

338 degree of renewable energy consumption. Due to the fact that the National Bureau of

339 Statistics does not release official regional data on primary energy consumption, we attempt

340 to convert the secondary energy consumption, such as coke, gasoline and diesel, into ten

341 thousand tons of standard coal on the basis of the reference coefficient of various energy

342 sources. Thereafter, we subtract the total secondary energy consumption from the total

343 regional energy, and finally get the primary energy consumption of each province. The

344 specific folding standard coal coefficient is summarized in Table 3.

Table 3 The conversion standard coal reference coefficient of various secondary energy

\begin{tabular}{|c|c|c|c|c|c|c|c|}
\hline & Coke & Fuel oil & Gasoline & Kerosene & Diesel & $\begin{array}{l}\text { Liquefied } \\
\text { petroleum } \\
\text { gas }\end{array}$ & $\begin{array}{c}\text { Power } \\
\text { (equivalent) }\end{array}$ \\
\hline $\begin{array}{l}\text { Coefficient } \\
\text { of } \\
\text { conversion }\end{array}$ & $\begin{array}{c}9,714 \\
\text { tons of } \\
\text { standard }\end{array}$ & $\begin{array}{c}14,286 \text { tons } \\
\text { of standard } \\
\text { coal / ten }\end{array}$ & $\begin{array}{c}14,714 \text { tons } \\
\text { of standard } \\
\text { coal / ten }\end{array}$ & $\begin{array}{c}14,714 \text { tons } \\
\text { of standard } \\
\text { coal / ten }\end{array}$ & $\begin{array}{c}14,571 \text { tons } \\
\text { of standard } \\
\text { coal / ten }\end{array}$ & $\begin{array}{c}17,143 \text { tons } \\
\text { of standard } \\
\text { coal / ten }\end{array}$ & $\begin{array}{c}0.1229 \\
\text { kilogram } \\
\text { standard }\end{array}$ \\
\hline
\end{tabular}




\begin{tabular}{ccccccc}
\hline $\begin{array}{c}\text { to standard } \\
\text { coal }\end{array}$ & $\begin{array}{c}\text { coal / ten } \\
\text { thousand } \\
\text { tons }\end{array}$ & $\begin{array}{c}\text { thousand } \\
\text { tons }\end{array}$ & $\begin{array}{c}\text { thousand } \\
\text { tons }\end{array}$ & $\begin{array}{c}\text { thousand } \\
\text { tons }\end{array}$ & tons & tons \\
& & & & kilowatt hour \\
\hline
\end{tabular}

Note: The conversion standard coal coefficient of various energy sources comes from the latest formally implemented on June 1, 2008. consumption of the renewables TES, energy intensity Energy and the level of regional economy advance GDP. Among them, the calculation method of renewable energy consumption has been described above. Referring to the research results of Qi(2010),

$353 \mathrm{Hu}(2011)$ and other scholars, the energy intensity is expressed by total energy expenditure as a percentage of GDP. In addition, regional economic development level is represented by regional per capita income, which has also been recognized by most scholars. read a large number of relevant literatures and finally decided to add the following control indicators into the model. (1) Government intervention GOV. The government participates in regional economic activities through fiscal policy which is represented by the taxation, thus supporting the development of environmental protection enterprises and green technology innovation. But in the short term, given the hidden competition between regions for economic revenue and the performance of local officials, governments may be more focused on economic favors than environmental benefits. Hence, the impact of government intervention on the green development is uncertain. Referred to Hong et al. (2014), the research adopts the percentage of government spending in GDP excluding public expenditures on technology, 
intervention. (2) Level of informatization ICT. Advances in information technology can availably solve the problem of information island, and the network information platform can provide opportunities for both supply and demand to integrate information, thus improving their resource allocation efficiency and effectively promoting the process of low carbon economy. from both the productive and the living ends. For another, The construction of various new digital infrastructure also forces certain pressure on the regional economic growth and the improvement of ecological performance, with rampant discussions on the "productivity paradox". Therefore, there remains indeterminacy about the relationship between the level of informatization and the advancement of green economy. In light of research results of Huang et al. (2019), Yuan and Liu (2019), the percentage of post and telecommunications business volume in gross population is calculated to indicate ICT . (3) Level of urbanization $U R B$. On the one hand, with the growing urbanization process, abundant factors, such as capital and labor, are constantly aggregating, which is conducive to the optimization of resource allocation and knowledge spillover, and thus can motivate the green economy. On the other hand, the pollution effect of infrastructure brought by urbanization and the congestion effect caused by factor agglomeration will inhibit the low-carbon economy development. Therefore, the impact of urbanization on the advancement of LC economy remains still dubious. Referred to the measurement methods of Zhang et al. (2015), this study employs the percentage of urban permanent residents in the general population to express the level of regional urbanization. (4) The population density POP. According to the theory of classical economics and new economics, the population size is often taken as the representation variable of labor force, which is one of the basic components 
389

390

391

392

393

394

395

396

397

of economic increase. Yet, there has been no consensus in the linkage between the population and LC development. This paper introduces the population intensity into the control factor, which is described as the ratio of the total resident population at the end of the year to the area of the province (Qiu and Zhou 2020). (5)Environmental regulation REG. Traditional neoclassical economists generally believed that environmental regulation would inhibit the development of low-carbon economy through "cost effect" and "constraint effect", while Porter put forward that reasonable environmental regulation could encourage enterprises to carry out the relevant technological innovation, so as to realize the coordinated progress of economic growth and ecological environment. Due to the uncertain relation between the two, this paper then uses the amount of pollution control divided by GDP to express the indicator of environmental regulation(Wang 2016). (6)Degree to openness Open. The export-oriented economy characterized by import and export trade is an important engine of China's rapid economic growth. But in fact, China's foreign trade activities are mainly manifested in the labor-intensive and resource-intensive export trade, and the "three imports and one supplement" low-technology foreign investment, which is not beneficial for sustainable evolution. Thereby, the degree of openness is also taken as the control variable in the model, and the calculation method of Shen (2017) is applied for reference.

Table 4 The definition and measurement of variables

\begin{tabular}{ccc}
\hline Variable name & Variable meaning & Variable measurement \\
\hline$L C E$ & The level of low-carbon & Super-SBM \\
& economic development &
\end{tabular}




$$
\text { energy }
$$

Energy

The intensity of energy use

GDP

The level of economy

$$
\text { development }
$$

GOV

The degree of government

intervention

ICT

The level of informatization

The density of population

POP

$R E G$

regulation

Open based on energy consumption

Energy consumption per unit of

GDP

GDP per capita

Government spending as a share

of GDP

The ratio of post and

telecommunications volume to

total population

The percentage of permanent

city residents in the general

population

The ratio of the total resident

people at year-end to the size

under provincial jurisdiction

The level of environmental The ratio of the total amount of

pollution control to GDP

The degree of openness

The total imports and exports

divided by gross domestic

product 


\subsection{Data source}

Setting the year from 2000 to 2017 as the research period, this paper selects 30 mainland regions in China as the research data. Because of the obvious information missing in Hong Kong, Taiwan, Tibet and Macao, we have eliminated them. On the one hand, this time span covers the period from the "10th Five-Year Plan" to the "13th Five-Year Plan", which has a wide range of statistical significance. On the other hand, the period selected crosses two rounds of "electricity system reform" and the initial stage of "structural reform on the supply side", which can fully verify the linkage between consumption of renewables and the process of LC economy in China.

The data of low-carbon and green growth processed in the study are almost obtained from China Statistical Yearbook and Wind - Economic Database. The consumption of various types of energy are primarily collected from National Energy Model Integration Platform of Beijing Institute of Technology, China Energy Statistical Yearbook and various public statistical information; The data of economic development level and control variables are referred to the sources, such as Population and Employment Statistical Yearbook of China, China Statistical Yearbook and Annual Database by Provinces on the website of the National Bureau of Statistics.

For sake of the weakness of data credibility and comparability caused by price fluctuations, the paper sets the base period as 2000, deflates the prices of all monetary quantities, and adjusts them to comparable prices by means of a basket of price indexes such as fixed asset investment price indexes. Moreover, for fear of the heteroscedasticity and multicollinearity, the logarithm processing is carried out on the related variables. Table 5 
430

431

432

433

434

435

436

437

438

439

440

441

442

Table 5 The specific descriptive statistics of the correlation coefficient matrix

\begin{tabular}{cccccc}
\hline Variable & Mean & standard deviation & Min & Max & Sample volume \\
\hline LCE & 0.9986 & 0.0713 & 0.6865 & 1.1864 & 540 \\
TES & 0.1178 & 0.1095 & 0.0006 & 0.4278 & 540 \\
Energy & 1.2480 & 0.7350 & 0.2546 & 4.3065 & 540 \\
GDP & 3.0835 & 2.4162 & 0.2645 & 12.9060 & 540 \\
GOV & 0.1470 & 0.0707 & 0.0058 & 0.4997 & 540 \\
ICT & 0.1375 & 0.1052 & 0.0095 & 0.6256 & 540 \\
URB & 0.4919 & 0.1524 & 0.1389 & 0.8961 & 540 \\
POP & 0.0429 & 0.0610 & 0.0007 & 0.3826 & 540 \\
REG & 0.0017 & 0.0014 & 0.0007 & 0.0099 & 540 \\
Open & 0.3091 & 0.3822 & 0.0162 & 1.6802 & 540 \\
\hline
\end{tabular}

\section{Empirical analysis of the threshold effect of renewable energy consumption}

\section{on low-carbon economic development}

\subsection{Results of panel variables testing}

\subsubsection{Multicollinearity test}

First, the correlation analysis is conducted. It can be seen from the Table 6 that there is no strong correlation between the variables, among which correlation coefficients are all less than 0.8 . Among them, the highest correlation coefficient is 0.7909 , which is between the indicator of $G D P$ and $U R B$.

Table 6 Correlation matrix and summary statistics of variables

\begin{tabular}{|c|c|c|c|c|c|c|c|c|c|c|}
\hline Variable & $L C E$ & TES & Energy & $G D P$ & GOV & $I C T$ & $U R B$ & $P O P$ & $R E G$ & Open \\
\hline$L C E$ & 1.000 & & & & & & & & & \\
\hline TES & $0.1016^{* *}$ & 1.000 & & & & & & & & \\
\hline Energy & $-0.4018^{* * *}$ & $-0.0914^{* *}$ & 1.000 & & & & & & & \\
\hline$G D P$ & $0.4203^{* * *}$ & $-0.086^{*}$ & $-0.5885^{* * *}$ & 1.000 & & & & & & \\
\hline GOV & $0.1671^{* *}$ & $0.3523^{* * *}$ & $0.2281^{* * *}$ & 0.0437 & 1.000 & & & & & \\
\hline
\end{tabular}




\begin{tabular}{|c|c|c|c|c|c|c|c|c|c|c|}
\hline$I C T$ & $0.4086^{* * *}$ & -0.0407 & $-0.4808^{* * * *}$ & $0.744^{* * * *}$ & 0.0245 & 1.000 & & & & \\
\hline$U R B$ & $0.349^{* * *}$ & $-0.142^{* *}$ & $-0.5164^{* * *}$ & $0.7909^{* * *}$ & -0.06 & $0.7146^{* * *}$ & 1.000 & & & \\
\hline$P O P$ & $0.0998^{*}$ & $-0.2499^{* * *}$ & $-0.3236^{* * *}$ & $0.5172^{* * *}$ & $-0.2107^{* * *}$ & $0.5056^{* * *}$ & $0.4879^{* * *}$ & 1.000 & & \\
\hline$R E G$ & $-0.1308^{* *}$ & $-0.1307^{* *}$ & $0.5234^{* * *}$ & $-0.2815^{* * *}$ & $0.0976^{* *}$ & $-0.2387^{* * *}$ & $-0.2084^{* * *}$ & $-0.2009^{* * *}$ & 1.000 & \\
\hline Open & $0.1545^{* *}$ & $-0.1775^{* * *}$ & $-0.3624^{* * *}$ & $0.4357^{* * * *}$ & $-0.307^{* * *}$ & $0.5868^{* * *}$ & $0.6032^{* * *}$ & $0.6999^{* * *}$ & $-0.1722^{* *}$ & 1.000 \\
\hline
\end{tabular}

443 Note: The statistical values at $10 \%, 5 \%$ and $1 \%$ levels are indicated by ${ }^{*},{ }^{* *}$ and ${ }^{* * *}$ respectively.

444 Secondly, the variance inflation factor VIF is analyzed. For the variables in the paper, the

445 VIF test results of variance inflation factor are set out in Table 7. Among all variables, the

446 maximum VIF value is 4.46 , much less than 10 . What is certain is that, combining with the

447 results of correlation coefficient and variance inflation factor VIF, it appears no

448 multicollinearity among variables (Wang and Liu 2007).

449

Table 7 VIF of each variable

\begin{tabular}{ccccccccccc}
\hline & TES & Energy & GDP & GOV & ICT & URB & POP & REG & Open & Mean \\
\hline VIF & 1.36 & 2.33 & 4.46 & 1.55 & 2.93 & 3.69 & 2.41 & 1.41 & 3.13 & 2.59 \\
$1 / \mathrm{VIF}$ & 0.74 & 0.43 & 0.22 & 0.65 & 0.34 & 0.27 & 0.41 & 0.71 & 0.32 & 0.45 \\
\hline
\end{tabular}

450

$451 \quad$ 5.1.2 Unit root test

452 For fear of spurious regression, the unit root test must be carried out before regression

453 analysis of panel model. Actually, there are many methods for unit root test, including the

454 tests of LLC, IPS, Breitung, Fisher-ADF and Fisher-PP, etc. In order to prevent the possible

455 defects brought by a single test method, the special tests whose null assumption is the

456 existence of panel unit root are respectively applied in this paper for variables through the

457 software EViews 9.0. According to Table 8, under the original value test, only three variables

458 ( $L C E, G O V, R E G)$ have passed the three tests at the significance level below $10 \%$, while the

459 other variables all had unit roots. In the case of first-order difference test, all statistics pass the

460 four tests at the significance level of less than $5 \%$, indicating that all of variables have 
461 stationarity after the first-order difference processing, which behaves as a comprehensive

462 first-order integer.

463

Table 8 The results of panel unit root test

\begin{tabular}{|c|c|c|c|c|c|c|c|c|}
\hline \multirow[t]{2}{*}{ Variable } & \multicolumn{4}{|c|}{ Untreated original value } & \multicolumn{4}{|c|}{ The value after the first difference } \\
\hline & LLC & IPS & ADF-Fisher & Fisher-PP & LLC & IPS & ADF-Fisher & Fisher-PP \\
\hline$L C E$ & $-2.31^{* *}$ & $-9.15^{* * *}$ & $192.09^{* * * *}$ & $225.09^{* * * *}$ & $-43.08^{* * *}$ & $-41.50^{* * * *}$ & $494.91^{* * * *}$ & $583.24^{* * *}$ \\
\hline TES & $-1.81^{* *}$ & $-2.04^{* *}$ & $99.01^{*}$ & 88.33 & $-9.60^{* * * *}$ & $-9.70^{* * *}$ & $199.16^{* * *}$ & $298.03^{* * *}$ \\
\hline Energy & $-3.80^{* *}$ & -0.82 & $74.96^{*}$ & $76.42^{*}$ & $-9.50^{* * *}$ & $-7.93^{* * *}$ & $167.71^{* * * *}$ & $234.87^{* * *}$ \\
\hline$G D P$ & $-4.69^{* * *}$ & 0.32 & 61.07 & $84.7045^{* *}$ & $-7.70^{* * * *}$ & $-1.89^{* *}$ & $79.79^{* *}$ & $90.21^{* *}$ \\
\hline GOV & $-2.77^{* *}$ & $-1.91^{* *}$ & $90.40^{* *}$ & $99.34^{*}$ & $-15.76^{* * *}$ & $-14.58^{* * *}$ & $268.48^{* * *}$ & $353.42^{* * *}$ \\
\hline$I C T$ & 0.10 & -0.58 & 52.92 & 53.23 & $-16.36^{* * *}$ & $-11.72^{* * * *}$ & $221.40^{* * * *}$ & $224.86^{* * *}$ \\
\hline$U R B$ & 6.44 & -0.20 & 70.07 & $105.52^{* *}$ & $-125.45^{* * *}$ & $-33.78^{* * *}$ & $227.54^{* * * *}$ & $335.32^{* * *}$ \\
\hline$P O P$ & $-4.82^{* * * *}$ & 0.73 & $91.35^{*}$ & 57.60 & $-6.30^{* * *}$ & $-3.52^{* * * *}$ & $118.96^{* *}$ & $124.72^{* * * *}$ \\
\hline$R E G$ & $-10.04^{* * * *}$ & $-9.46^{* * *}$ & $182.35^{* * *}$ & $157.35^{* * *}$ & $-21.85^{* * *}$ & $-19.22^{* * *}$ & $338.58^{* * *}$ & $419.59^{* * *}$ \\
\hline Open & $-4.54^{* * * *}$ & -0.87 & 67.69 & 38.44 & $-13.88^{* * *}$ & $-11.07^{* * *}$ & $215.27^{* * *}$ & $320.70^{* * *}$ \\
\hline
\end{tabular}

464 Note: The statistical values at $10 \%, 5 \%$ and $1 \%$ levels are indicated by ${ }^{*},{ }^{* *}$ and ${ }^{* * *}$ respectively.

$465 \quad 5.1 .3$ Co-integration test

466 As can be seen from Table 9, the KAO test method is used to perform the co-integration

467 test on the variables of the three basic models respectively. Once the value of $\mathrm{P}$ is smaller than

4680.01 , we can believe that the null assumption is statistically rejected, that is, all the indices in

469 each model are co-integrated over the long term.

470

Table 9 Co-integration test - KAO test results

\begin{tabular}{cccc}
\hline Statistic & Model & T-Statistic & Prob. \\
\hline \multirow{3}{*}{ ADF } & Model (1) & -6.65117 & 0.0000 \\
& Model (2) & -5.76695 & 0.0000 \\
& Model (3) & -5.1202 & 0.0000 \\
\hline
\end{tabular}

471 


\subsubsection{Threshold effect test}

474

475

476

477

478

479

480

481

482

483

484

\begin{tabular}{|c|c|c|c|c|c|c|c|c|}
\hline \multirow{2}{*}{ Model } & \multirow{2}{*}{$\begin{array}{c}\text { Threshold } \\
\text { variable }\end{array}$} & \multirow{2}{*}{$\begin{array}{c}\text { Threshold } \\
\text { effect }\end{array}$} & \multirow{2}{*}{ F-value } & \multirow{2}{*}{$\mathrm{P}$-value } & \multirow{2}{*}{$\begin{array}{c}\text { BS } \\
\text { number }\end{array}$} & \multicolumn{3}{|c|}{ The critical value } \\
\hline & & & & & & 0.01 & 0.05 & 0.10 \\
\hline \multirow{2}{*}{ Model (1) } & \multirow{2}{*}{$T E S$} & Single & $15.88^{* *}$ & 0.0400 & 300 & 13.7399 & 15.2373 & 20.7347 \\
\hline & & Double & 10.35 & 0.1900 & 300 & 13.9775 & 17.6793 & 26.7207 \\
\hline \multirow{2}{*}{ Model (2) } & \multirow{2}{*}{ Energy } & Single & $16.46^{* *}$ & 0.0300 & 300 & 10.9593 & 12.9263 & 19.5390 \\
\hline & & Double & 5.69 & 0.5733 & 300 & 12.2030 & 13.9146 & 19.1169 \\
\hline \multirow{2}{*}{ Model (3) } & \multirow{2}{*}{$G D P$} & Single & $36.14^{* *}$ & 0.0167 & 300 & 21.8923 & 27.1765 & 38.5323 \\
\hline & & Double & 3.78 & 0.8300 & 300 & 12.6770 & 14.5299 & 17.6840 \\
\hline
\end{tabular}

485 Note: The statistical values at $10 \%, 5 \%$ and $1 \%$ levels are indicated by ${ }^{*},{ }^{* *}$ and ${ }^{* * *}$ respectively.

486

When the $5 \%$ quantile of the threshold variable is taken as the starting point of the search,

487 the threshold variable value with the minimum sum of squares of residuals is the right

488 estimation of threshold. After the threshold estimator is obtained, it is also necessary to verify

489 the similarity between the estimated threshold and the real value. Table 11 displays the test 
results. It is found that when the threshold variable is set as the consumption of renewables $T E S$, the test value of single threshold effect is 0.0093 , and the corresponding $95 \%$ confidence intervals are respectively [0.0091, 0.0099]; While the intensity of energy consumption Energy is set as the threshold variable, the value of the critical value is 1.1766 , whose $95 \%$ confidence intervals is between 1.1078 and 1.1815; Under the adjustment effect of economic development level GDP variable, a single threshold 0.6366 is obtained, which is in the $95 \%$ confidence interval of 0.6074 to 0.6444 .

Table 11 The results of threshold estimates

\begin{tabular}{ccccc}
\hline Model & $\begin{array}{c}\text { Threshold } \\
\text { variable }\end{array}$ & Test & $\begin{array}{c}\text { Threshold } \\
\text { estimates }\end{array}$ & $\begin{array}{c}0.95 \text { confidence } \\
\text { interval }\end{array}$ \\
\hline Model (1) & TES & Single threshold value & 0.0093 & {$[0.0091,0.0099]$} \\
Model (2) & Energy & Single threshold value & 1.1766 & {$[1.1078,1.1815]$} \\
Model (3) & $G D P$ & Single threshold value & 0.6366 & {$[0.6074,0.6444]$} \\
\hline
\end{tabular}

To acquire the threshold and the confidence interval in a more intuitive way, we further identify the threshold value by feat of the least square likelihood ratio statistic LR. The threshold estimate is the statistic when LR is zero. Figure 1 presents the likelihood ratio function graphs covering the threshold value in the three kinds of threshold models respectively.

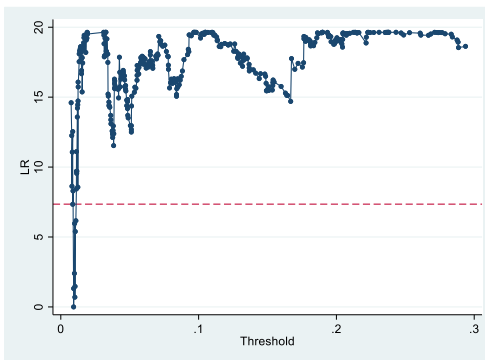

Model (a)

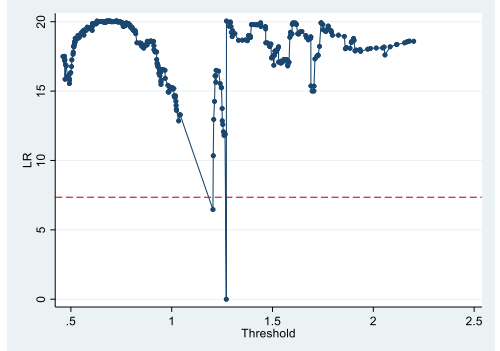

Model (2) 
505

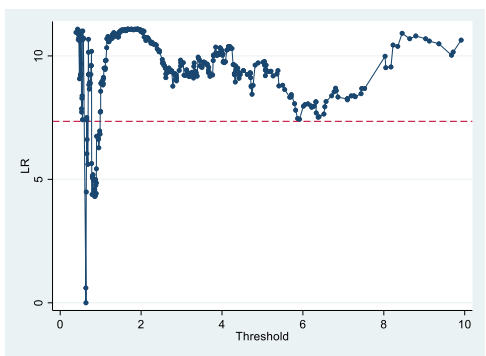

Model (3)

Fig.1. The function graphs of Likelihood ratio of threshold values in different models (1),

$$
\text { (2) and (3) }
$$

\subsubsection{Analysis of the threshold regression model}

On the basis of different threshold variables, this article establishes three threshold panel models. Table 12 demonstrates the concrete results of three panel regressions.

In Model (1), when the consumption of the renewables is low $\left(T E S_{i t} \leq 0.0093\right)$, it appears unfavorable for the progress of LC economy. (-8.0152), which is significant at the $1 \%$ level; When TES gets greater $\left(T E S_{i t}>0.0093\right)$, the blossom of low-carbon economy will be driven by renewable energy consumption, with the elastic coefficient 0.1034 passing the 0.1 siginificance test. Hereby, we can easily conclude that there is a complex nonlinear correlation between the consumption of renewable energy sources and the growth of low-carbon economy, which is regulated by the process of energy structure adjustment. As the consumption of the renewable source steps over the inflection point, the direction of the influence of the renewable share on the LC economy advancement will change from negative to positive evidently. Therefore, the Hypothesis 1 in this paper is further verified.

In terms of the results of Model (2), along with a relative lower intensity of energy use Energy $_{i t} \leq 1.1766$ ), the renewable sources consumption can make strong thrust for the green 
524

525

development effectively (0.1233), and it has passed the significance level test of 0.01 ; while along with a relative higher intensity of energy use $\left(\right.$ Energy $\left._{i t}>1.1766\right)$, renewable energy consumption is no longer beneficial to low-carbon economy development, conversely showing an insignificant negative effect. It is not difficult to conclude that renewable energy consumption is highly susceptible by energy consumption intensity, thus generating a non-linear shock on the green economy progress. Once the degree of dependence on traditional energy sources reaches a special critical value, the two core indicators studied in this paper present an influence of structural mutation, which is reflected in the fact that the renewables consumption no longer wields a remarkable influence on the low-carbon economy evolution, thus convincingly confirming the Hypothesis 2.

In the case of a relatively low level of economic development $\left(G D P_{i t} \leq 0.6366\right)$, the consumption of renewable sources will inhibit the progress of LC economy, whose elasticity coefficient is -0.2108 , as shown in Model (3); It is worth noticing that moderated by a better economic advance $\left(G D P_{i t}>0.6366\right)$, the consumption of renewables in turn significantly advance the process of low carbon economy, with an influence coefficient of 0.1326 which is significant at 0.05 level. Taking the indicator of GDP as the threshold variable, the existence of a non-simple linear correlation between the renewables consumption and green economic advance has been confirmed. On both sides of the threshold of economic growth, the influence of renewable resources consumption on the advancement of low-carbon economy is obviously opposite, and it reaches the expected effect in the later stage, empirically proving the Hypothesis 3 proposed above.

Table 12 The regression results of three thresholds models 


\begin{tabular}{|c|c|c|c|}
\hline Variable & Model (1) & Model (2) & Model (3) \\
\hline \multirow{2}{*}{ GOV } & $0.2712^{* *}$ & $0.2436^{* *}$ & 0.1012 \\
\hline & $(2.97)$ & $(2.63)$ & $(1.08)$ \\
\hline \multirow{2}{*}{ ICT } & $0.2727^{* * *}$ & $0.2707^{* * *}$ & $0.2394^{* * *}$ \\
\hline & $(6.32)$ & (6.19) & $(5.58)$ \\
\hline \multirow{2}{*}{$U R B$} & $0.15577^{* * *}$ & $0.1760^{* * *}$ & $0.2061^{* * *}$ \\
\hline & (3.79) & $(4.27)$ & $(5.10)$ \\
\hline \multirow{2}{*}{$P O P$} & $-1.47067^{* * *}$ & $-1.4983^{* * *}$ & $-1.5160^{* * *}$ \\
\hline & $(-4.29)$ & $(-4.33)$ & $(-4.51)$ \\
\hline \multirow{2}{*}{$R E G$} & 1.2716 & 2.3173 & 0.9156 \\
\hline & $(0.47)$ & $(0.83)$ & $(0.35)$ \\
\hline \multirow{2}{*}{ Open } & $0.05037^{* *}$ & $0.0473^{*}$ & 0.0331 \\
\hline & (1.98) & $(1.84)$ & $(1.32)$ \\
\hline \multirow{2}{*}{$T E S_{i t} \leq 0.0093$} & $-8.0152^{* * *}$ & & \\
\hline & $(-3.85)$ & & \\
\hline \multirow{2}{*}{$T E S_{i t}>0.0093$} & $0.1034^{*}$ & & \\
\hline & $(1.88)$ & & \\
\hline \multirow{2}{*}{ Energy $_{i t} \leq 1.1766$} & & $0.1233^{* * *}$ & \\
\hline & & $(2.21)$ & \\
\hline \multirow{2}{*}{ Energy $_{i t}>1.1766$} & & -0.0014 & \\
\hline & & $(-0.02)$ & \\
\hline \multirow{2}{*}{$G D P_{i t} \leq 0.6366$} & & & $-0.2108^{* *}$ \\
\hline & & & $(-2.73)$ \\
\hline \multirow{2}{*}{$G D P_{i t}>0.6366$} & & & $0.1326^{* *}$ \\
\hline & & & $(2.45)$ \\
\hline \multirow[t]{2}{*}{ cons } & $0.8805^{* * *}$ & $0.8750^{* * *}$ & $0.8913^{* * *}$ \\
\hline & $(3.60)$ & $(3.08)$ & $(4.61)$ \\
\hline
\end{tabular}
detailed results are collected in Table 13. 
low-carbon economy has been fully evident in that all 30 regions in China had entered the high level range of renewable consumption. Nevertheless, the consumption standards of the renewables in Inner Mongolia and Shanxi declined significantly and fell back in the transitional low-level range until 2017. In particular, this paper argues that Inner Mongolia and Shanxi are two provinces with obvious fossil energy endowment, and the harmonious situation among economy and ecology in Shanxi province is seriously restricted by its leading industrial chain of coal, coke and steel, which shows an energy rebound effect in the long-term process of renewable energy consumption; Secondly, As far as the intensity of energy consumption is concerned, there are 24 regions reaching the high range in 2000 , while only four provinces remain until the year of 2015 and 2016. Notably, Shanxi province crossed back into the zone of high-level intensity in 2017. Similar to the above analysis, this study argues that it mainly root in the strong dependence of fossil fuels in Shanxi Province. On the whole, the energy consumption intensity in the vast majority of regions in China does not step over the critical value, which manifests that these regions may well get rid of the energy dependence, showing a relative weak effect of energy path dependence; Thirdly, considering the standards of economic advance, it shows a half of the regions were in the low level range at the beginning, while only Guizhou province is left by 2005. It can be seen intuitively that until 2010, all regions in China have entered a new span of economic development levels with no rebound.

Generally, in most provinces in China, the large-scale energy transition measures have reaped good benefits and effectively promoted green growth, but there are still some regions that need to reduce their energy intensity. Hence, under the background of "new normal", it is 


\begin{tabular}{|c|c|c|c|c|c|c|}
\hline Threshold ranges & 2000 & 2005 & 2010 & 2015 & 2016 & 2017 \\
\hline$T E S_{i t} \leq 0.0093$ & 5 & 3 & 0 & 0 & 0 & 2 \\
\hline$T E S_{i t}>0.0093$ & 25 & 27 & 30 & 30 & 30 & 28 \\
\hline Energy $_{i t} \leq 1.1766$ & 6 & 10 & 21 & 26 & 26 & 25 \\
\hline Energy $_{i t}>1.1766$ & 24 & 20 & 9 & 4 & 4 & 5 \\
\hline$G D P_{i t} \leq 0.6366$ & 15 & 1 & 0 & 0 & 0 & 0 \\
\hline$G D P_{i t}>0.6366$ & 15 & 29 & 30 & 30 & 30 & 30 \\
\hline
\end{tabular}

absolutely an critical step to realize the transition of energy consumption, so as to accelerate the intensive transition of economic advance mode in China.

Table 13 The amount of regions within each threshold interval in the sample period

\subsection{Robustness test}

581

582 
Table 14 The results of robustness tests

\begin{tabular}{|c|c|c|c|}
\hline Variable & Model 1 & Model (2) & Model (3) \\
\hline \multirow{2}{*}{ GOV } & $0.305^{* *}$ & $0.2157^{*}$ & 0.2094 \\
\hline & $(2.63)$ & $(1.79)$ & $(1.77)$ \\
\hline \multirow{2}{*}{$I C T$} & $0.2032^{* * *}$ & $0.2172^{* * * *}$ & $0.2040^{* * *}$ \\
\hline & $(4.49)$ & $(4.78)$ & $(4.52)$ \\
\hline \multirow{2}{*}{$U R B$} & $0.2144^{* * *}$ & $0.2395^{* * *}$ & $0.2145^{* * *}$ \\
\hline & $(4.38)$ & $(4.88)$ & $(4.39)$ \\
\hline \multirow{2}{*}{$P O P$} & $-1.6529^{* * *}$ & $-1.6990^{* * * *}$ & $-1.5505^{* * *}$ \\
\hline & $(-4.66)$ & $(-4.76)$ & $(-4.35)$ \\
\hline \multirow{2}{*}{$R E G$} & 1.5075 & 2.4653 & 0.0152 \\
\hline & $(0.50)$ & $(0.81)$ & $(0.34)$ \\
\hline \multirow{2}{*}{ Open } & 0.0339 & $0.0318^{*}$ & 0.0297 \\
\hline & $(1.33)$ & $(1.23)$ & $(1.16)$ \\
\hline \multirow{2}{*}{$T E S_{i t} \leq 0.0102$} & $-8.175^{* * *}$ & & \\
\hline & $(-4.00)$ & & \\
\hline \multirow{2}{*}{$T E S_{i t}>0.0102$} & $0.1142^{*}$ & & \\
\hline & $(1.92)$ & & \\
\hline \multirow{2}{*}{ Energy $_{i t} \leq 1.6967$} & & $0.1115^{*}$ & \\
\hline & & $(1.86)$ & \\
\hline \multirow{2}{*}{ Energy $_{i t}>1.6967$} & & -0.1591 & \\
\hline & & $(-1.46)$ & \\
\hline \multirow{2}{*}{$G D P_{i t} \leq 0.6366$} & & & $-0.1875^{* *}$ \\
\hline & & & $(-1.97)$ \\
\hline \multirow{2}{*}{$G D P_{i t}>0.6366$} & & & $0.1376^{* *}$ \\
\hline & & & $(2.32)$ \\
\hline \multirow[t]{2}{*}{ cons } & $0.8720^{* * *}$ & $0.8727^{* * *}$ & $0.8808^{* * * *}$ \\
\hline & $(3.05)$ & $(9.39)$ & $(9.80)$ \\
\hline
\end{tabular}

Note: The statistical values at $10 \%, 5 \%$ and $1 \%$ levels are indicated $b y{ }^{*},{ }^{* *}$ and ${ }^{* * *}$ respectively.

\section{Discussion}

In line with the general theory, the change of energy consumption structure will exert

597 influence on many factors to a certain extent, such as enterprise energy cost, economic profit

598 and environmental benefit (Shen and Li 2020). Many studies have explored the impact of different types of energy use on the green economy, such as fossil energy consumption, clean 
600

601

602

603

604

605

606

607

608

609

610

611

612

613

614

615

616

617

618

619

620

621

energy development, and non-fossil energy consumption (Irene and Marco 2019). Yet, in terms of the available literature, there are still some divergences in conclusions concerning the association between energy consumption and the system of economy and society. Arguably, this study provides a new perspective on the basis of regional heterogeneity regulation, obtaining that due to the particularity of different regions, the renewable energy consumption affects the development of low-carbon economy differently.

Firstly, in terms of the renewables consumption, it will affect the development of low-carbon economy inordinately in different stages, and even cause a complete change in the direction of influence. The reason for this may lie in a wide-ranging and complex energy transition system. In the process of new energy supply and energy use, great capital support is undeniably required, which is highlighted by the renewal of infrastructure and the improvement of technical capacity. Under the pressure of high-cost facilities, technologies and crafts, the government has to invest huge amounts of subsidies to encourage the consumption of non-fossil energy, which seriously aggravates the financial burden of the government and partly transfers it to downstream enterprises and end consumers, thus generating a large base effect on other government and private sector expenditures and consumption. Therefore, renewable energy consumption presents a certain economic cost in the early stages. With the increasing proportion of non-fossil energy consumption, the scale effect and dry-learning effect of energy transformation are gradually manifested due to the initial cost allocation, the accumulation of technological capital, and the diffusion of cleaner production technology, thus forming a well-functioning $3 \mathrm{E}$ system with greater energy efficiency, higher economy quality and better ecological environment. Hence, only high 
622

623

renewable energy consumption can effectively promote the low-carbon progress of the economy.

$$
\text { Secondly, in view of the limited moderating effect of energy intensity, it is essential to }
$$
give full consideration to energy intensity when discussing the correlation between the consumption of the renewables and the green development. In regions of high energy consumption intensity, economies can hardly do without fossil energy consumption, which can easily bring about a high degree of dependence and internal inertia of the system. Thereby, in the course of the gradual replacement of fossil fuels by non-fossil fuels, these regions are bound to face formidable obstacles to clean energy technology innovation and renewable energy consumption, which is likely create a serious divide among regions. The areas with low energy consumption intensity not only rely less on energy consumption, but also have lower economic costs to replace fossil fuels with clean energy, thus showing a greater substitution effect. It follows that when the energy intensity achieves a certain height, the driving effect of the renewables consumption on the development of green economy is relatively limited, which is also an issue that the regional government ought to put particular effort into during the project of energy transition.

Thirdly, the regional economic advancement does play a big part in the effect of the renewable energy consumption on the green advancement. We conjecture that the reason may be that the high standards of economy growth is often associated with a more reasonable industrial structure and intensive development mode, which is in favor of the evaluation of the non-fossil energy. Driven by the awareness of ecological preservation and the demand for green, the input and inflow of factor featured by technology, talent and knowledge are more 
644

645

smooth in these regions, which makes the innovation of green technology reveal unparalleled advantages. Gradually, more benefits are emerging, including higher levels of cleaner production, lower research and development costs, and greater energy efficiency. Accordingly, it is necessary to coordinate the transition to clean energy and the advancement of economy.

\section{Conclusions and suggestions}

Considering the effects including energy substitution effect, path dependence effect and technology base effect, this study explores the complicated role of the renewable consumption in the provincial low-carbon economic development in China. Using China's inter-provincial panel data and setting the research period as 2000 to 2017, this paper empirically probes into the nonlinear correlation between the two core variables respectively moderated by the indicator of renewable energy utilization, energy consumption intensity and the economic development level. As a result, all the three hypotheses put forward in the study have been empirically confirmed and the following findings are obtained. (1)In the path of realizing the transformation of energy structure, the negative externalities resulting from fossil energy use force economies into an unsustainable state. However, with the gradual replacement of fossil energy by renewable energy, it gradually appears more positive externalities of energy consumption, showing more favorable influence on the progress of green economy; (2)The long-term extensive economic growth mode in China has resulted in the lock-in effect of fossil energy use, especially in the mid-west areas, forming a developmental pattern of quantity growth rather than quality growth. More often than not, renewable energy consumption is more beneficial to the green economy in regions that are less dependent on 
regional economic heterogeneity, which makes the basic conditions of renewable energy consumption differ in varying degrees, and thus has the opposite effect on the social low-carbon and green development. As can be seen from the empirical research results, for regions with better economy conditions, the driving impact of the renewables consumption on the low-carbon economy is more apparent.

In consideration of the above findings, this paper believes that efforts can be made from the following three aspects to push the utilization of renewable energy sources and boost the evaluation of China's green economy.

On the one hand, for regions where traditional polluting energy consumption still occupies a large proportion, the development of non-fossil energy may cause certain economic losses due to high economic costs. In such regions, the country ought to accelerate the energy transition through appropriate policy interventions and perfect supporting mechanisms, so as to enhance the potential of economic growth. For instance, the government can subsidize the production of non-fossil energy such as photoelectricity and wind power, meantime a corresponding mechanism should be established to restrain the producer. Unlike fossil fuels, renewable energy needs to be turned into electricity before it can be utilized by both the producing and consuming sectors. Yet, on account of the cost disadvantage of the renewables, it is more necessary to subsidize producers such as photoelectric and wind power. However, under the background of imperfect system and management, subsidy policies are prone to breed "subsidy" behavior, that is, some producers will take advantage of policy loopholes to steal state subsidies. Therefore, the government needs to continuously improve relevant systems and management to give full play to the due effectiveness of subsidy 
policies.

On the other hand, for regions with high energy consumption intensity, efforts should be made to break the path dependence on energy consumption, improve the technical quality of exploration and application of non-fossil energy resources, and strengthen the infrastructure and institutional construction of non-fossil energy transportation and Internet, so as to promote the transformation of economic development model and enhance the potential of low-carbon economic development. Drived by the rapid development of industry and the gradual expansion of cities, people have higher requirements for high-energy products such as steel and cement, which in turn has advanced the development of energy-intensive enterprises. Accordingly, policy documents such as Made in China 2025 and China's 13th Five-Year Plan for Economic and Social Development stress the elimination of outdated production facilities and supported the development of strategic emerging industries. In order to get rid of regional energy dependence and break the locking effect of fossil fuels on economic growth, the government is obliged to focus on promoting the transformation and improvement of industries to foster intensive economic progress. For one thing, instead of the blind expansion of high-energy industries, the government should raise the access standards for high-input and low-output industries, and transform and upgrade high-carbon industries. For another, some financial means, such as tax relief and financial credit, can be adopted to stimulate the development of intelligent manufacturing and high-tech industries, thus accelerating the internal resource restructuring and structural upgrading of the industry.

Moreover, proceeding from the reality of unbalanced regional development, the government has to adhere to the principle of implementing energy policies with clear 
boundaries and formulates renewable energy consumption strategies by category based on the actual economic conditions of different regions. Particularly in the regions with low-income economies, the progress of clean fuels is faced with greater institutional obstacles and practical difficulties. In regions with such characteristics, the government should further reinforce the intensity of both subsidies and support, enhance the confidence of enterprises to drive the energy transition strategy, thereby stimulating a moderate transition of the energy structure.

\title{
Ethics approval
}

$$
\text { Not applicable }
$$

\section{Consent for participate}

$$
\text { Not applicable }
$$

\section{Consent for publication}

$$
\text { Not applicable }
$$

\section{Conflict for publication}

\author{
Not applicable
}

\section{Conflict of interest}

I declared that we have no conflicts of interest in this work.

\section{Author Contributions}

Conceptualization: [Li tuochen Shi Ziyi]; Methodology: [Shi ziyi Han dongri]; Software: 
[Shi Ziyi]; Writing-original draft: [Shi ziyi]; Writing-review and editing: [Shi ziyi Han dongri]; Supervision: [Li tuochen]

\section{Acknowledgments}

We are very grateful to editors and anonymous reviews for reviewing this paper.

\section{Funding}

This work was supported by the National Social Science Fund Project (17ZDA119), the National Social Science Fund (17AGL009), the Ph.D. Student Research and Innovation Fund of the Fundamental Research Funds for the Central Universities (3072020GIP0914) and Scientific research fund of education department of Liaoning province (JQW201915402).

\section{Availability of data and materials}

All data can be downloaded from China's National Bureau of Statistics.

\section{References}

Arthur WB (1994) Increasing returns and path dependence in economy. Michigan: University of Michigan Press.

Al-mulali U, Fereidouni HG, Lee JY et al (2013) Examining the bi-directional long run relationship between renewable energy consumption and GDP growth. Renewable and Sustainable Energy Reviews 22(8): 209-222.

Armeanu DS, Vintila G, Gherghina SC (2017) Does renewable energy drive sustainable economic growth? Multivariate panel data evidence for EU-28 countries. Energies 10(3):381.

Bowden N, Payne J (2010) Sectoral analysis of the causal relationship between renewable and non-renewable energy consumption and real output in the US. Energy Sources, Part B: Economics, Planning, and Policy 5(4):400-408. 
Cai Y, Sam CY, Chang T (2018) Nexus between clean energy consumption, economic growth and CO2 emissions. Journal of Cleaner Production 182:1001-1011.

David PA (1988) Path-dependence: putting the past into the future of economics. California: Standford University Press.

Destek MA (2016) Renewable energy consumption and economic growth in newly industrialized countries: Evidence from asymmetric causality test. Renewable Energy 95: $478-484$.

Hansen BE (1999) Threshold effects in non-dynamic panels: Estimation, testing, and inference. Journal of Econometrics 93(2):345-368.

Han DR, Li TC, Feng SS et al. (2020) Does renewable energy consumption successfully promote the green transformation of China's industry? Energies 13.

He YD, Lin BQ (2019) Investigating environmental Kuznets curve from an energy intensity perspective: Empirical evidence from China. Journal of Cleaner Production 234(10):1013-1022.

Huang BN, Hwang MJ, Yang CW et al (2008) Casual relationship between energy consumption and GDP growth revisited : a dynamic panel data approach. Ecological Economics 67(1):41-54.

Huang QH, Yu YZ, Zhang SL (2019) Internet development and productivity growth in manufacturing industry: International mechanism and China experiences. China Industrial Economics (08):5-23.

Hong GX, Zhang LT, Li WJ (2014) Regional heterogeneity of the effect of financial agglomeration on total factor. Economic Survey 31(04):7-12.

Irene M, Marco R (2019) The impact of phasing out fossil fuel subsidies on the low-carbon transition. Energy Policy 124:355-370.

Inglesi-Lotz R (2016) The impact of renewable energy consumption to economic growth: A panel data application. Energy Economics 53:58-63.

Koak E,Aykutarkgünei (2017) The renewable energy and economic growth nexus in Black Sea and Balkan counties. Energy Policy 100:51-57.

Li JJ, Cheng WJ (2020) Comparison of life-cycle energy consumption, carbon emissions and economic costs of coal to ethanol and bioethanol. Applied Energy 277. 
Li WW, Yi PT (2020) Assessment of city sustainability - Coupling coordinated development among economy, society and environment. Journal of Cleaner Production 256.

Li K, Qiao H (2011) Structural and efficiency effects on the change of energy consumption intensity in Shandong province. China Population, Resources and Environment 21(05):164-169.

Luan BJ, Zou H, Chen SX et al (2021) The effect of industrial structure adjustment on China's energy intensity: Evidence from linear and nonlinear analysis. Energy, 218.

Lee CC, Chang CP (2007) Energy consumption and GDP revisited: a panel analysis of developed and developing countries. Energy Economics 29(6): 1206-1223.

Liu K, Bai HK, Yin S, Lin BQ (2018). Factor substitution and decomposition of carbon intensity in China's heavy industry. Energy 145.

Lin MS (2017) The clean energy consumption, environment governance and the sustainable economic growth in china. The Journal of Quantitative \& Technical Economics $34(12): 3-21$.

Ma LM, Shi D, Pei QB (2018) Low-carbon transformation of China's energy in 20152050:renewable energy development and feasible path. China Population, Resources and Environment 28(02):8-18.

Naqvi SAA, Shah SAR, Anwar S et al (2020) Renewable energy, economic development, and ecological footprint nexus: fresh evidence of renewable energy environment Kuznets curve (RKC) from income groups. Environmental Science and Pollution Research 1-21.

Omri A, Belaïd F (2021) Does renewable energy modulate the negative effect of environmental issues on the socio-economic welfare? Journal of Environmental Management 278.

Omri A, Ben Mabrouk N, Sassi-Tmar A (2015) Modeling the causal linkages between nuclear energy, renewable energy and economic growth in developed and developing countries. Renewable and Sustainable Energy Reviews 42:1012-1022.

Ocal O, Aslan A (2013) Renewable energy consumption - economic growth nexus in Turkey. Renewable and Sustainable Energy Reviews 28(Complete) : 494-499.

Presley K, Wesseh Jr, Lin BQ (2020) Energy substitution and technology costs in a transitional economy. Energy 203. 
Qi SZ, Li Y (2017) Does renewable energy consumption affect economic growth? : Empirical evidence from European union. World Economy Studies (04):106-119+136.

Qi SZ, Li Y (2018) Threshold effects of renewable energy consumption on economic growth under energy transformation. China Population, Resources and Environment 28(02):19-27.

Qi SZ, Li K (2010) An analysis on the relation between the energy consumption intensity and the economic growth in developing countries. World Economy Studies (02):8-13+87.

Qiu LX, Zhou JM (2020) Temporal and spatial differentiation and influencing factors of eco-efficiency at country scale in Zhejiang province. East China Economic Management 34(10):11-20.

Shen GY (2017) Foreign direct investment, opening to the outside world and the quality of economic growth--based on the empirical empirical study of china's automobile industry. Inquiry into Economic Issues (10):113-122.

Shen B, Li X (2020) Financial development, industrial structure upgrading and energy efficiency improvement. Inquiry into Economic Issues (12):131-138.

Shen YC, Yue SJ, Sun SQ et al (2020) Sustainable total factor productivity growth: The case of China. Journal of Cleaner Production 256.

Sikder A, Inekwe J, Bhattacharya M (2019) Economic output in the era of changing energy-mix for G20 countries: New evidence with trade openness and research and development investment. Applied Energy 235:930-938.

Tan DM, He HQ (2016) Emergy ecological footprint analysis of energy consumption of China. Economic Geography 36(08):176-182.

Teng XL, Rong J (2020) Research on the Comprehensive Evaluation of Low Carbon Economic Development in Shandong Province Based on the Weighted Gra-topsis Method. Journal of Finance Research 4(1).

Unruh GC (2000) Understanding carbon lock-in. Energy Policy 28(12):817-830.

Wang HQ (2016) Study on threshold effects of environmental regulation on economic growth from the perspective of human capital. China Soft Science (06):52-61.

Wang XH, Liu Y (2007) China's energy consumption and economic growth: A study based on the cointegration analysis and granger causality test. Resources Science (05):57-62. 
Wang ZL, Xia CX, Xia YH (2020) Dynamic relationship between environmental regulation and energy consumption structure in China under spatio temporal heterogeneity. Science of The Total Environment 738.

Xie FM, Liu ZL, Chen HY et al (2018) Threshold Effects of New Energy Consumption Transformation on Economic Growth. Sustainability 10(11).

Xu G, Schwarz P, Yang H (2020) Adjusting energy consumption structure to achieve China's CO2 emissions peak. Renewable and Sustainable Energy Reviews 122.

Xiao H, Ma Z, Zhang P et al (2019) Study of the impact of energy consumption structure on carbon emission intensity in China from the perspective of spatial effects. Natural Hazards 99(3):1365-1380.

Yan ZM, Zou BL, Du K et al (2020) Do renewable energy technology innovations promote China's green productivity growth? Fresh evidence from partially linear functional-coefficient models. Energy Economics 90.

Yang Z, Abbas Q, Hanif I et al (2021) Short-and long-run influence of energy utilization and economic growth on carbon discharge in emerging SREB economies. Renewable Energy $165(1): 43-51$.

Yang C, Zhu YL (2016) Ecological deficit based on new energy-based ecological footprint model in Hunan Province. China Population, Resources and Environment 26(07):37-45.

Yuan HX, Liu YB (2019) Financial agglomeration and green development efficiency: A two-dimensional perspective based on level and efficiency. Science Research Management 40(12):126-143.

Zhang C, Shi D, Wang JJ (2015) Estimation and decomposition of the potential improvement of carbon productivity from the angle of outer environment and inner management. Resources Science 37(06):1218-1229.

Zhao HL, Lin BQ (2019) Will agglomeration improve the energy efficiency in China' s textile industry: Evidence and policy implications. Applied Energy 237:326-337

Zhou ZJ, Hu JH (2013) Evaluation of low carbon economy development efficiency based on a super -SBM model. Resource Science 35(12):2457-2466.

Zhu H, Zheng J, Zhao QY et al (2020) Economic Growth,Energy Structure Transformation and Carbon Dioxide Emission: Empirical Analysis based on panel data. Research on 
Economics and Management 41(11):19-34. 
Figures

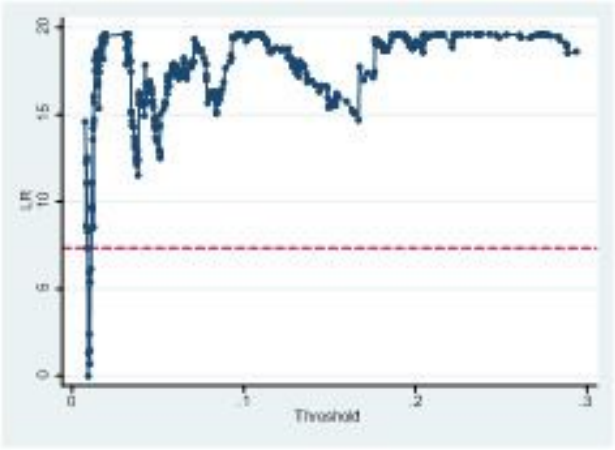

Model (a)

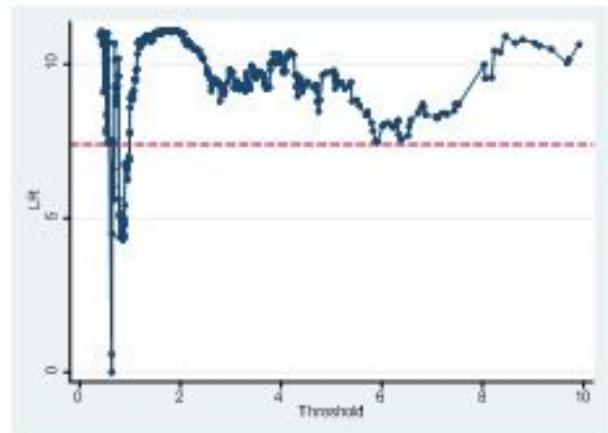

Model (3)

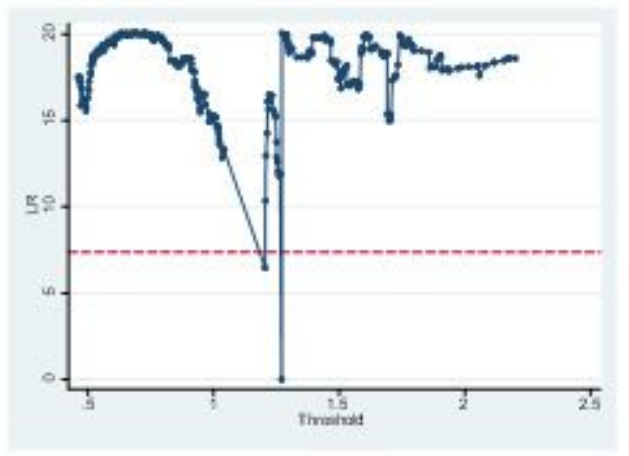

Model (2)

\section{Figure 1}

The function graphs of Likelihood ratio of threshold values in different models (1), (2) and (3) 